\title{
Child growth and duration of breast feeding in urban Zambia
}

\author{
Nicholas H Ng'andu, Theresa E E Watts
}

\begin{abstract}
Study objective-The aim was to investigate the relationship between duration of breast feeding and growth of children.

Design-The study was a survey of randomly selected clusters of households.

Setting-The study was community based and took place in an urban township with a population of over 43000 people in Lusaka, the capital city of Zambia.

Participants-The sample consisted of 438 children aged 0 to 59 months surveyed between October 1984 and June 1986. Due to missing information, 394 children were used in the analysis.

Measurements and main results-After controlling for confounding variables, duration of breast feeding was found to be associated with height for age among children in their first two years of life, but not in the later years of life. There was no significant protective effect of breast feeding on undernutrition and acute malnutrition as measured by weight for age and weight for height.

Conclusions-The findings suggest that, in this community, duration of breast feeding is strongly associated with the linear growth experiences of children and the association changes with the infant's age. One strong risk factor suspected to be responsible for the poor growth performance of children in this study is the low nutritional quality of the weaning foods which are used to supplement breast milk during the lengthy weaning period.
\end{abstract}

"My baby deserves the best, so I breast feed longer". " The decisions of women to breast feed are greatly influenced by attitudes and images, especially those coming through the mass media. The importance of women having access to complete, accurate, and unbiased information about breast feeding cannot be overemphasised. This does not, however, guarantee that the information will be used, nor that it will provide health benefits if the advice is followed.

Research has shown that breast feeding provides not only the nutritional essentials for a child's development but also some protection against infection ${ }^{23}$ and infant death from infectious diseases. ${ }^{4}$ Also the interaction between mother and child is important for emotional development. As a result of current research, an increased awareness of the benefits of breast feeding has developed and a need to provide facilities for working mothers to continue to breast feed their children, even when working away from home, has been realised.
One of the most important factors that influence the impact of breast feeding is its duration. ${ }^{2}$ Several studies have examined the adequacy of breast feeding as a sole source of food during the first six months of life and have shown that a child of six months needs at least one litre of breast milk, which is often not available. ${ }^{56}$ Also the statement that prolonged breast feeding (breast feeding over 12 months) is sufficient by itself for the rising nutrient needs (and declining stores) of the rapidly growing infant, ${ }^{7}$ has been challenged by the finding that it was associated with clinical and anthropometric malnutrition. ${ }^{67}$ Other studies have also suggested that the apparent increase in malnutrition among prolonged breast fed children was either due to an inadequate weaning $\operatorname{diet}^{8}$ or to the confounding effects of adverse social conditions. ${ }^{89}$

Information remains incomplete, especially from developing countries, about the beneficial effects of prolonged breast feeding. This study describes the association between duration of breast feeding and child growth in a population based sample of children in an urban area in a developing country.

\section{Methods}

The study was conducted in George township, a periurban community in Lusaka, the capital city of Zambia. This township is made up of over 140 sections with at least 25 houses in each section and has over 43000 people who live in simple two or three room houses constructed of concrete blocks or mud bricks and roofed with corrugated asbestoscement, usually held down with stones. Each house is on a plot of approximately 10 square metres. Little land area exists for gardens, though most people try to grow some food around their houses and in the stony area on the periphery of the township. All houses have access to a pit latrine, either sharing with another household or outright owning of one, and there is a public stand post of chlorinated water for every 25 houses. This township was upgraded in 1978 when roads and markets were constructed and water supplies made available and in November 1984 a health centre was opened to serve the area. For the current study 15 sections were selected at random from a list of 140 known sections. All households were interviewed in each of the selected sections. A total of 350 households were surveyed between October 1984 and June 1986. Twenty five households were not surveyed because these houses had been abandoned, turned into shops or had not yet been completely constructed. This sample of 15 sections represents $10 \%$ of the total number of known sections and it yielded a total of 438 children aged 0 to 59 months. Details of the study area and methods of data collection have been published elsewhere. ${ }^{10}$ 
Household socioeconomic information was collected by interviewing the head of the household or, in case of his/her absence, another senior household member. Information collected included current demographic, environmental, and socioeconomic characteristics of the family and their utilisation of health services.

The socioeconomic status and cultural values of the sections surveyed are similar to other sections in George township and they are also similar to other sections in other townships of Lusaka. The average household consists of six persons, and 97\% of the total population are Zambians, the remainder being immigrants from neighbouring countries. Most families cannot afford adequate weaning foods. The economy of the country has been worsening with prices of basic essentials going up due to inflation.

The most common occupations of the households are driving (buses, taxis, government vehicles, etc, $14.8 \%)$, manual work $(19.1 \%)$ and self-employment $(43.6 \%)$ mainly as petty traders in markets. For the heads of household, 10.9\% had received no education and $21.9 \%$ of their wives had received no education. The child's mother ( $93 \%$ of interviews) or a close relative answered questions on the duration of breast feeding and other matters relating to the child.

Of the children in this study, $87 \%$ were either sons or daughters of the head of the household, $9 \%$ were grandsons/daughters and $4 \%$ were other relations of the head of the household.

Each child was weighed at the time of the interview with a calibrated Salter type 0-25 kg spring scale reading to the nearest $100 \mathrm{~g}$. Supine length was measured with a specially constructed measuring board, which reads to the nearest $0 \cdot 1$ cm for children under 24 months of age, and standing height was taken for children aged 24 months or more. The Center for Disease Control (CDC) anthropometric software package was used to express each child's nutritional status as a number of standard deviations (SD score) above or below the median of the reference population. The CDC anthropometric analysis software is based on the NCHS reference population. ${ }^{11}$ These standards have been shown to be suitable for use as reference for assessing nutritional status of children under five years in developing countries. $^{1213}$

Duration of breast feeding was defined as the age reached when breast feeding completely stopped. A child was considered adequately immunised if he/she had received the correct number of doses of BCG (tuberculosis vaccine), poliomyelitis, DPT (diphtheria, pertussis, tetanus), and measles vaccines. The age and immunisation status of the child was checked using the "road to health card", and $58 \%$ of the children had these cards at the time of the interview.

\section{STATISTICAL ANALYSIS}

To determine the median age at stopping breast feeding and the proportions of children still being breast fed at given ages, a survival analysis approach was employed, using data on current age and reported age at cessation of breast feeding.

Because of the complexity of the association between weaning and growth, the data were stratified by age into two broad age groups. The first group comprised the "young" children $(\leqslant 24$ months of age), the second group consisted of the "older" children ( $>24$ months of age). Among the "young" children some were still being breast fed, whereas others were completely weaned off the breast at the time of the survey. These data allowed examination of the question among children of each age (by six month age groups): Is the nutritional status better or worse in those who were still being breast fed compared with completely weaned children? Among the "older" children, all had been weaned at the time of the survey, but at different ages. The question was: Among children of each age (by six month age groups), is there an association between current nutritional status and duration of breast feeding? This question examines the long term effects of early feeding practices. Interactions with age were not tested in either of the two groups because of the small sample sizes.

The variables (table I) believed to be potential confounders were first tested for significant associations with the child's nutritional status, after adjusting for age of the child using two way analysis of variance (ANOVA). The variables controlled for in the analyses are shown in table II. These variables showed significant associations $(p<0.05)$ with child growth in either of the two groups of children for any of the three nutritional indices and were introduced in the analysis recorded as shown in table II.

Adjusted deviations were calculated using the multiple classification analysis (MCA) technique. ${ }^{14}$ This technique is a version of the multiple regression analysis that estimates the mean value of the dependent variable for each category of the independent variable. The adjusted deviations show deviations from the grand mean for each factor level of the independent variable. They indicate the magnitude of the effect of each factor level after the variation due to other factors has been adjusted for. ${ }^{14}$ Statistical analyses were carried out using SPSS/TM statistical package on an IBM XT machine. ${ }^{14}$

\section{Results}

In the initial survey, 438 children aged 0 to 59 months were included. The mean age was $26 \cdot 3$ months, SD $16 \cdot 3$. Due to missing information, 34 children $(7 \cdot 8 \%)$ were excluded from the analysis, leaving a total of 394 children.

The figure shows the averages of SD scores in relation to age of the child. Height for age and weight for age varied substantially with age, but weight for height compared well with the standard. The heights of children for all age groups were on average 0.5 standard deviations below the NCHS standards, whereas for those aged 18-23 months they were two standard deviations below the standards. The variations in mean SD scores with age were statistically significant for height for age, and weight for age ( $p<0.01$ ), but not for weight for height (one way ANOVA, $p>0.11$ ), in both "young" and "older" children and for the two groups combined. Overall, the prevalence of stunted growth appears to increase steadily from two to five years and it is maximal in the third year of life. 
Table I Variables suspected to be confounding the association between child growth and duration of breast feeding $\star$

Sex of child

Current age of child (months)

Maternal age (years)

Maternal education level

Number of pregnancies

Father/guardian education level

Father's/guardian's age (years)

* These variables were tested for significant association with child growth in each of the two groups of children using one way analysis of variance

Table II Distribution of variables controlled for in the analysis

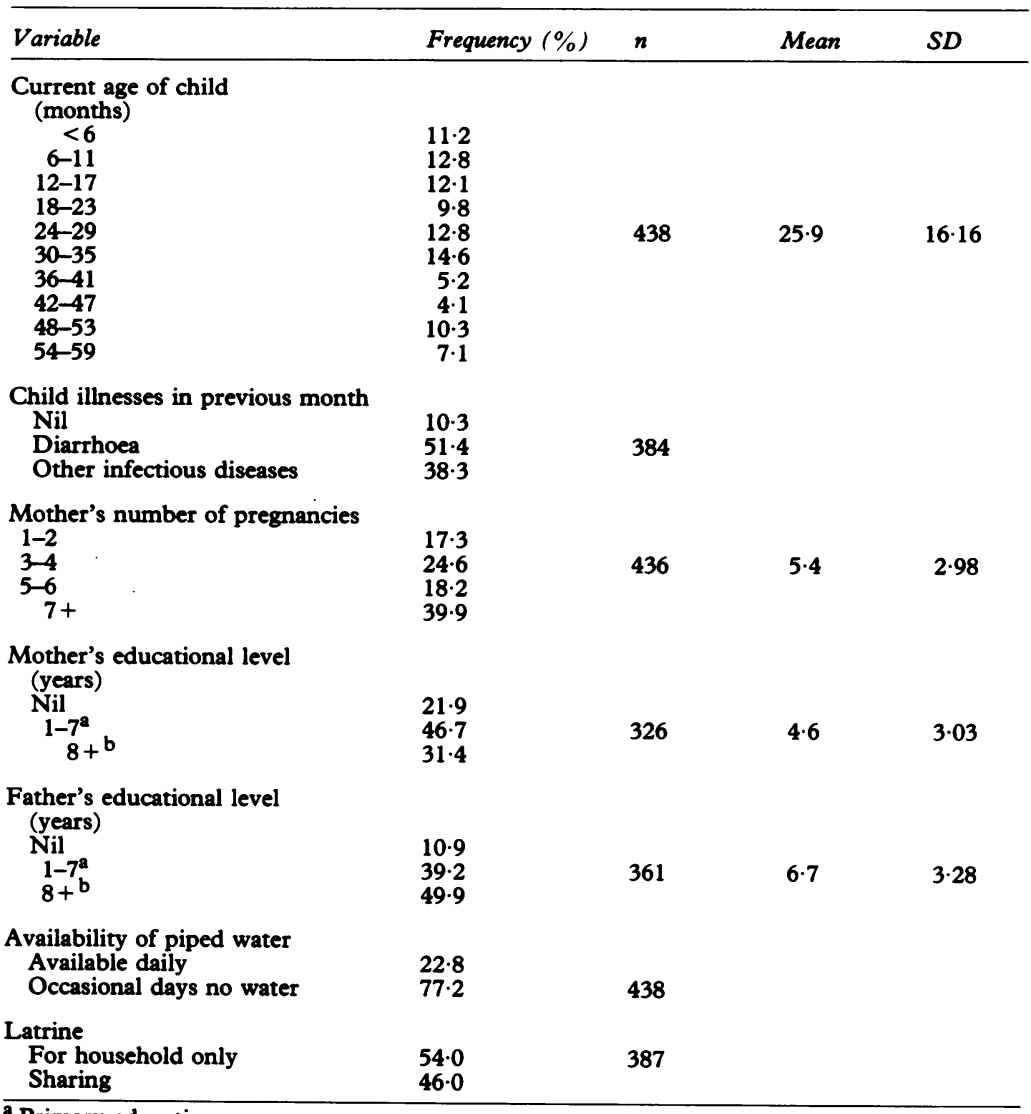

Primary education

Secondary/technical education

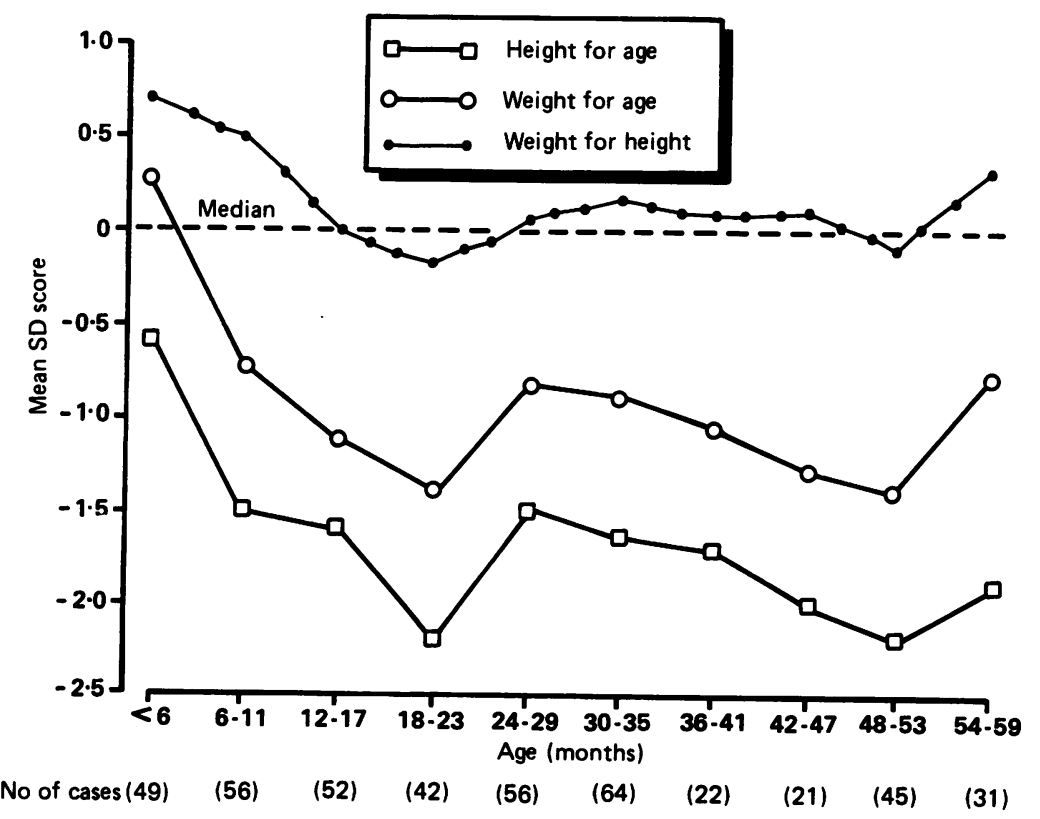

Mean SD score by age of the child
Table III shows the relationship between duration of breast feeding and age of the child. Among those infants below 12 months at the time of the survey, only two had stopped breast feeding; one, aged six months, stopped breast feeding at three months because of illness, and the other child, aged 5 months, stopped breast feeding at two months because the mother was ill.

Using survival analysis methods, the median age at cessation of breast feeding was estimated to be 18.3 months and the proportions of children still breast feeding at the ages of 12,18 , and 24 months were $91.2 \%, 65.5 \%$, and $13.3 \%$, respectively. The four children older than 24 months who were reported to be still breast feeding at the time of the survey (table III) were not included in the subsequent stratified analyses.

Table IV shows the associations between duration of breast feeding and child growth after controlling for current age of the child. Among the "young" children ( 24 months of age or less), who were completely weaned off the breast at the time of the survey, the duration of breast feeding had positive effects on height for age and weight for age and negative effects on weight for height, whereas for currently breast fed children the duration of breast feeding had a positive effect on weight for height (table IV). Overall, the duration of breast feeding had statistically significant effects on height for age only (table IV). Among the "older" children (over 24 months of age), no pattern exists in adjusted effects by duration of breast feeding for all the three nutritional indices and no significant associations were found between duration of breast feeding and any of the three nutritional indices (table IV).

The apparent associations between duration of breast feeding and indicators of nutritional status were further investigated by controlling for potentially confounding factors using ANOVA. Due to missing data, 38 children $(8.4 \%)$ were excluded from this analysis.

Among the "young" children, a statistically significant association was found between duration of breast feeding and height for age (table V). For children who were completely weaned at the time of the survey, breast feeding had positive effects on height for age and weight for age, and negative effects on weight for height. Among the "older" children, no pattern exists in adjusted effects by duration of breast feeding for all the three nutritional indices and there were no statistically significant associations between duration of breast feeding and any of the three nutritional indices (table $\mathrm{V}$ ).

\section{Discussion}

This study shows that the mean SD scores of height for age, weight for age, and weight for height steadily decreased up to the age of 24 months (figure). These results suggest a significant degree of stunting, which represents the accumulated consequences of retarded growth which do not become evident until two years of age. The more severely delayed patterns of height for age may have occurred because linear growth is a slower process than growth in body mass. ${ }^{12}$ The data also show that the prevalence of wasting is greatest between 12 and 24 months of age. 
Table III Duration of breast feeding by age of child

\begin{tabular}{lcccccc}
\hline $\begin{array}{l}\text { Current } \\
\text { age }\end{array}$ & \multicolumn{2}{l}{ Duration of breast feeding (months) } & & \\
\cline { 2 - 5 } (months) & $<12$ & $12-17$ & $18-23$ & $24+$ & Breast ${ }^{\mathrm{a}}$ & Total \\
\hline$<12$ & 2 & 0 & 0 & 0 & 101 & 103 \\
$12-17$ & 1 & 6 & 0 & 0 & 37 & 44 \\
$18-23$ & 4 & 9 & 12 & 0 & 9 & 34 \\
$24-35$ & 10 & 19 & 39 & 10 & 4 & 82 \\
$36+$ & 9 & 28 & 64 & 12 & 0 & 113 \\
Total & 26 & 62 & 115 & 22 & 151 & $376^{\text {b }}$ \\
\hline
\end{tabular}

Still breast feeding

bome children had missing information

Wasting most likely results from dietary deficiencies and diarrhoeal diseases, which are known to be more frequent during this period and tend to decrease later in childhood. ${ }^{12}$ The nonsignificant trends in mean SD scores for weight for height by age relate to the fact that this index is age independent. The distributions of the SD scores of children by age in this study are similar to those found in other studies of children between 0 and 59 months of age from developing countries. ${ }^{1516}$

The results of this study also show that, for "young" children, breast feeding had a significant effect on height for age, which is a measure of the duration of malnutrition. For children who were completely weaned at the time of the survey, duration had positive effects, and for those who were still being breast fed, duration had negative effects. This association is apparent even after controlling for possible confounding variables and it suggests that breast feeding beyond the first year of life does appreciably depress the child's linear growth.

The negative effects observed among "young" children who were still breast feeding at the time of the survey may be due to the fact that mothers were not supplementing enough with nutritious foods. Questions about supplementary and weaning foods were not asked. However, a two year cohort study of 250 children born in the University Teaching Hospital in Lusaka, living in the same area, has shown that the average age of introduction of supplementary and weaning foods was 3 months (Ng'andu $\mathbf{N}$ et al, unpublished observations, 1987). Weaning foods, generally, consist of maize meal porridge with sugar to taste. The average number of meals given to an infant up the age of 12 months in a day was three and increased to four for older children. A very small proportion of mothers added groundnuts, eggs or milk to the porridge. Nearly all children are breast fed and bottle feeding is not common.

The beneficial effects of duration of breast feeding on height for age and weight for age among those children who were completely weaned at the
Table IV Results of ANOVA analysis after controlling for current age of the child
Table $V$ Results of ANOVA analysis after controlling for confounding variables

\begin{tabular}{|c|c|c|c|c|c|c|}
\hline Model & $\begin{array}{l}\text { Age } \\
\text { (months) }\end{array}$ & $\begin{array}{l}\text { Grand } \\
\text { mean }^{\mathrm{a}}\end{array}$ & $\begin{array}{l}\text { Duration b } \\
\text { (months) }\end{array}$ & $n$ & $\begin{array}{l}\text { Adjusted } \\
\text { deviations }\end{array}$ & Significance \\
\hline Height for age & $\begin{array}{l}\leqslant 24 \\
>24\end{array}$ & $\begin{array}{l}-1.45 \\
-1.76\end{array}$ & $\begin{array}{c}\text { On breast }^{e} \\
\text { Weaned }^{\mathrm{e}} \\
<12 \\
12-17 \\
18-23 \\
24+\end{array}$ & $\begin{array}{r}122 \\
42 \\
17 \\
42 \\
75 \\
18\end{array}$ & $\begin{array}{r}-0.19 \\
0.55 \\
0.13 \\
-0.24 \\
0.14 \\
-0.16\end{array}$ & $\begin{array}{l}\mathrm{p}=0.023 \\
\mathrm{p}=0.419\end{array}$ \\
\hline Weight for age & $\begin{array}{l}\leqslant 24 \\
>24\end{array}$ & $\begin{array}{l}-0.74 \\
-1.02\end{array}$ & $\begin{array}{c}\text { On breast } \\
\text { Weaned } \\
<12 \\
12-17 \\
18-23 \\
24+\end{array}$ & $\begin{array}{r}122 \\
42 \\
17 \\
42 \\
75 \\
16\end{array}$ & $\begin{array}{r}-0.10 \\
0.29 \\
-0.14 \\
0.19 \\
0.02 \\
-0.44\end{array}$ & $\begin{array}{l}p=0.197 \\
p=0.094\end{array}$ \\
\hline Weight for height & $\begin{array}{l}\leqslant 24 \\
>24\end{array}$ & $\begin{array}{l}0.20 \\
0.13\end{array}$ & $\begin{array}{l}\text { On breast } \\
\text { Weaned } \\
<12 \\
12-17 \\
18-23 \\
24+\end{array}$ & $\begin{array}{r}122 \\
42 \\
17 \\
42 \\
75 \\
16\end{array}$ & $\begin{array}{r}0.11 \\
-0.32 \\
-0.28 \\
0.39 \\
-0.09 \\
-0.30\end{array}$ & $\begin{array}{l}p=0.291 \\
p=0.109\end{array}$ \\
\hline
\end{tabular}

arand mean: of dependent variables: height for age; weight for age, weight for height $b$ Duration of breast feeding

c Adjusted deviations for current age of child
d Significance assessed by ANOVA after allowance for current age of the child

e On breast: still breast feeding at the time of the survey

f On breast: still breast feeding at the time of the survey
Weaned: completely weaned off the breast at time of the survey

\begin{tabular}{|c|c|c|c|c|c|c|}
\hline Model & $\begin{array}{l}\text { Age } \\
\text { (months) }\end{array}$ & $\begin{array}{l}\text { Grand } \\
\text { mean }^{\mathrm{a}}\end{array}$ & $\begin{array}{l}\text { Duration } \\
\text { (months) }\end{array}$ & $n$ & $\begin{array}{l}\text { Adjusted } \\
\text { deviations }\end{array}$ & Significance $^{\mathrm{d}}$ \\
\hline Height for age & $\begin{array}{l}\leqslant 24 \\
>24\end{array}$ & $\begin{array}{l}-1.47 \\
-1.62\end{array}$ & $\begin{array}{l}\text { On breast }^{e} \\
\text { Weaned }^{\mathrm{f}} \\
<12 \\
12-17 \\
18-23 \\
24+\end{array}$ & $\begin{array}{r}11 \\
42 \\
16 \\
40 \\
72 \\
16\end{array}$ & $\begin{array}{r}-0.20 \\
0.52 \\
0.38 \\
-0.29 \\
0.21 \\
-0.15\end{array}$ & $\begin{array}{l}p=0.031 \\
p=0.412\end{array}$ \\
\hline Weight for age & $\begin{array}{l}\leqslant 24 \\
>24\end{array}$ & $\begin{array}{l}-0.74 \\
-1.03\end{array}$ & $\begin{array}{l}\text { On breast } \\
\text { Weaned } \\
<12 \\
12-17 \\
18-23 \\
24+\end{array}$ & $\begin{array}{r}111 \\
42 \\
16 \\
40 \\
72 \\
16\end{array}$ & $\begin{array}{r}-0.08 \\
0.20 \\
-0.17 \\
0.13 \\
0.06 \\
-0.42\end{array}$ & $\begin{array}{l}p=0.382 \\
p=0.632\end{array}$ \\
\hline Weight for height & $\begin{array}{l}\leqslant 24 \\
>24\end{array}$ & $\begin{array}{l}0.21 \\
0.01\end{array}$ & $\begin{array}{l}\text { On breast } \\
\text { Weaned } \\
<12 \\
12-17 \\
18-23 \\
24+\end{array}$ & $\begin{array}{r}111 \\
42 \\
16 \\
40 \\
72 \\
16\end{array}$ & $\begin{array}{r}0.15 \\
-0.39 \\
-0.44 \\
0.21 \\
-0.02 \\
-0.02\end{array}$ & $\begin{array}{l}p=0.211 \\
p=0.282\end{array}$ \\
\hline
\end{tabular}

a Grand mean: of dependent variables: Height for age; weight for age; weight for height

$b$ Duration of breast feeding

c Adjusted deviations for factors: current age child and all factors in table II

d Significance assessed by ANOVA after allowance for current age of the child and all factors in table II

e On breast: still breast feeding at the time of the survey

$f$ Weaned: completely weaned off the breast at time of the survey 
time of the survey may lie in the fact that mothers start to wean their children on fresh milk, porridge with groundnuts, and other foods until the time when the children are completely weaned off the breast and become accustomed to the normal (adult) diet, which contains a reasonable balance of nutrients. Such a diet helps support healthy long term growth experiences of the young child up to two years of life. The negative effects observed on weight for height may be attributed to the adverse effects of environmental conditions (insufficient nutrient intakes and other factors) to which the children are being constantly exposed to.

The results of this study also suggest that for "older" children the duration of breast feeding has no significant effects on any of the three nutritional indices and no pattern exists in effects across the duration groups for all the indices. Controlling for possible confounding variables did not alter the results. These results seem to suggest that, in this community, after the age of two years, duration of breast feeding does not appreciably affect the growth pattern of the child. This may be because of the reduced number of breast feeds in a day in older children.

A possible explanation for the absence of an effect of prolonged breast feeding on the long term growth experience of the child as measured by height for age may be that even if breast milk provides a valuable supplementary source of "complete" protein and of fat, calcium and vitamins, ${ }^{3}$ the poor overall economic conditions do not permit the provision of other high quality nutrient dense foods for the children. Consequently, the children have reduced rates of linear growth which cannot easily be avoided by breast feeding the child longer than 12 months.

Some of the explanations for the poor growth of children who have a prolonged period of breast feeding are that: (1) the mothers may be giving inadequate amounts of supplementary (weaning) foods; (2) the types of food supplements may be inadequate for the growth needs, or they may be contaminated, ${ }^{17}$ which results in repeated short term fluctuations in child growth; and (3) some mothers may breast feed for a longer duration if their children are too thin. ${ }^{3}$

Another explanation for growth delays of the children is that although breast feeding is continued well into the second year of life, most mothers are not effectively able to meet the nutritional requirements of their children through breast milk due to inadequacy of the maternal diet and the reduction in the average amount of milk consumed at each feed. ${ }^{18}$

A final potential explanation for the poor growth of children who were breast fed for prolonged periods is that a beneficial survival effect may be operating, by which breast fed malnourished children are more likely to survive than those who have been weaned ${ }^{19}$ (the infant mortality rate in this area is 86 per 1000 births $^{20}$ ). Such survival benefits may reside in the immune factors conveyed in the milk from the mother to the nursing child.

Several points must be borne in mind when interpreting the results from this study, such as the cross sectional nature of the study design, the relatively small sample size, the lack of information on some important variables like birth interval and weaning practices, and the fact that the accuracy of most of the information collected depends on memory recall of the respondent. These limitations are partly due to the fact that the study was not specifically designed to test this hypothesis.

In summary, from the results of this study one could say that duration of breast feeding has significant effects on the long term growth experience of the child in the first two years of life, the negative effects observed on currently breast fed children suggest that this must be accompanied by adequate, better quality, and uncontaminated weaning foods which may reduce or perhaps even eliminate the significant amount of stunting of these children. However, there is great need for an objective and non-dogmatic evaluation of this link in the developing world, using similar study designs and, possibly, using longitudinal data. The nonexistence of a negative association among the older children may be because as the age of the child increases, the association of breast feeding with growth of the child declines ${ }^{16}$ and also because of the small numbers we observed among the various groups of duration of breast feeding in older children.

We gratefully thank Dr B M Nkowane, of the Department of Community Medicine, Zambia, Professor J Anderson, Department of Nutrition, University of North Carolina at Chapel Hill, School of Public Health, USA, and Mr D Dunn of the London School of Hygiene and Tropical Medicine, UK, for their thoughtful comments and contribution during the preparation of the manuscript. We also thank the 6th year medical students who were involved in the interviews and lastly Mrs $\mathrm{H} \mathrm{Ng}$ 'andu for typing the manuscript. This research was funded by a grant from the University of Zambia.

1 UNICEF offices Zambia. Poster. August 1986

2 Mosley WH, Chen LC. Child survival: strategies for research. Population and Development Review 1984; 10 (suppl): 94-105.

Victoria CG, Vaughan JP, Martines JC, Barcelos LB. Is prolonged breast-feeding associated with malnutrition? Am J Clin Nutr 1984; 39: 307-14.

4 Victoria CG, Smith PG, Vaughan JP, et al. Evidence for protection by breast-feeding against infant deaths from infectious diseases in Brazil. Lancet 1987; ii: 319-21.

5 Waterlow JC, Thomson AM. Observation on the adequacy of breast-feeding. Lancet 1979; ii: 238-42.

6 Whithead RG. Nutritional aspects of human lactation. Lancet 1983; i: 167-9.

7 Jelliffe DB, Jelliffe P. Human milk in the modern world. Oxford: Oxford University Press, 1978: 84-160.

8 Jelliffe DB, Jelliffe EFP. The volume and composition of human milk in poorly nourished communities. A review. $\mathrm{Am}$ f Clin Nutr 1978; 31: 492-515.

9 Central Bureau of Statistics. The rural Kenyan nutrition survey. February-March 1977. Nairobi: Ministry of Finance and Planning, 1977: 7: 24-6 [Social Perspectives 2(4)].

10 Watts TEE. Some aspects of child health in an urban township, Lusaka, Zambia. F Trop Pediatr 1986; 32: 51-6.

11 Jordan MD. CDC anthropometric software package, based on the CDC Standard Deviation-derived growth reference curves; derived from NCHS/CDC refence Center for Disease Conrul

12 WHO Working Group. Use and interpretation 1986. anthropometric indicators of nutritional status. Bull WHO 1986; 64: 929-41.

13 World Health Organization. Measuring change in nutritional status. Guidelines for assessing the nutritional impact of supplementary feeding programmes for vulnerable groups. Geneva: WHO, 1983.

14 Norisis Mariya SPSS/PC+ TM: SPSS/PC+ for the IBM PC/XT/AT. Chicago: SPSS Inc, 1986.

15 Tomkins AM, Hayes RJ, Dunn DT, Pickering H. Socioeconomic factors associated with child growth in two seasons in an urban Gambia. Ecol Food Nutr 1986; 18: 107-16.

16 Jumaan AO, Serdula MK. Feeding practics and growth in Yemen children. I Trop Pediatr 1989; 35: 82-6.

17 Barnell RAE, Rowland MGM. Infant foods as a potential source of diarrhoeal illness in rural West Africa. Trans Roy Soc Trop Med Hyg 1979; 73: 85-90.

18 Whitehead RG, Rowland MGM, Hutton M, Prentice AM, Muller E. Paul A. Factors influencing lactation performance in rural Gambian mothers. Lancet 1978; ii: 178-81.

19 Briend A, Wotjtyniak B, Rowland MGM. Breast feeding, nutritional state and child survival in rural Bangladesh. Br nutritional state and child su
Med $\mathcal{J}$ 1988; 296: 879-81.

20 Central Statistics Office. Population and housing census of Zambia. Lusaka: Analytical report Vol III, 1980: 55. 